趴 


\section{Progress in Systems and Control Theory}

Volume 20

Series Editor

Christopher I. Byrnes, Washington University 


\title{
Computation and Control IV
}

\author{
Proceedings of the Fourth \\ Bozeman Conference, \\ Bozeman, Montana \\ August 3-9, 1994
}

K.L. Bowers and J. Lund

Editors

\author{
1995 \\ Birkhäuser \\ Boston $\bullet$ Basel $\bullet$ Berlin
}


Kenneth Bowers

Department of Mathematics

Montana State University

Bozeman, Montana 59717
John Lund

Department of Mathematics

Montana State University

Bozeman, Montana 59717

Printed on acid-free paper

(C) 1995 Birkhäuser Boston

Birkhäuser [0ำ

Softcover repritnt of the hardcover 1st edition 1995

Copyright is not claimed for works of U.S. Government employees.

All rights reserved. No part of this publication may be reproduced, stored in a retrieval system, or transmitted, in any form or by any means, electronic, mechanical, photocopying, recording, or otherwise, without prior permission of the copyright owner.

Permission to photocopy for internal or personal use of specific clients is granted by Birkhäuser Boston for libraries and other users registered with the Copyright Clearance Center (CCC), provided that the base fee of $\$ 6.00$ per copy, plus $\$ 0.20$ per page is paid directly to CCC, 222 Rosewood Drive, Danvers, MA 01923, U.S.A. Special requests should be addressed directly to Birkhäuser Boston, 675 Massachusetts Avenue, Cambridge, MA 02139, U.S.A.

ISBN-13: 978-1-4612-7586-2 e-ISBN-13: 978-1-4612-2574-4

DOI: $10.1007 / 978-1-4612-2574-4$

Typeset by the Authors in Latex 


\section{CONTENTS}

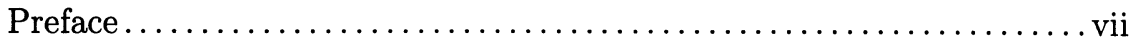

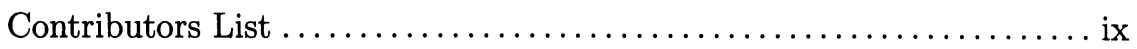

Well-Posedness for a One Dimensional Nonlinear Beam

H.T. Banks, D.S. Gilliam and V.I. Shubov .................. 1

Modeling and Parameter Estimation for an Imperfectly Clamped Plate

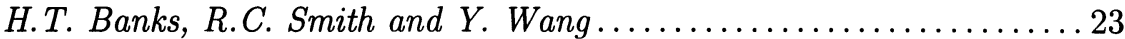

Discretization of Cost and Sensitivities in Shape Optimization

J. Burkardt, M. Gunzburger and J. Peterson ..................43

Representation of Feedback Operators for Hyperbolic Systems

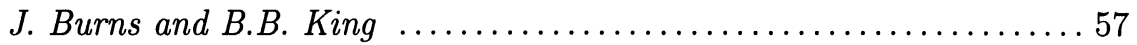

Steady State Response to Burgers' Equation with Varying Viscosity C.I. Byrnes, D. Gilliam, V. Shubov and Z. Xu

A Weighted Mixed-Sensitivity $H_{\infty}$-Control Design for Irrational Transfer Matrices

R. Curtain and $Y$. Zhou

Acuity of Observation of the Heat Equation on a Bounded Domain A. DeStefano, S. Kaliszewski and D.I. Wallace ................ 115

Designing Controllers for Infinite-Dimensional Systems with Finite-Dimensional Control System Design Tools M.A. Erickson and A.J. Laub

Preserving Exponential Stability Under Approximation for Distributed Parameter Systems R.H. Fabiano

A Comparison of Estimation Methods for Hydraulic Conductivity Functions from Field Data

B.G. Fitzpatrick and J.A. King... 155

An Adpative Stencil Finite Differencing Scheme for Linear First Order Hyperbolic Systems - A Preliminary Report R.H. Hoar and C.R. Vogel. 
Eigenvalue Approximations for Sturm-Liouville Differential Equations with Mixed Boundary Conditions M. Jarratt

Existence of Functional Gains for Parabolic Control Systems B.B. King

Binocular Observability

P. Lockwood and C. Martin

Dynamics of Ocular Motion

S. Lu and C. Martin

The Sinc-Galerkin Schwarz Alternating Method for Poisson's Equation N. Lybeck and K. Bowers ............................... 247

A Cross Validation Method for First Kind Integral Equations B.A. Mair and F.H. Ruymgaart

Linear Control Theory, Splines and Interpolation

C. Martin, P. Enqvist, J. Tomlinson and Z. Zhang

Sinc Aproximation of Solution of Heat Equation with Discontinuous Initial Condition

A. Morlet and F. Stenger

Exact Boundary Controllability of a Beam and Mass System

S.W. Taylor ...................................... 305

A Multigrid Method for Total Variation-Based Image Denoising

C.R. Vogel

Parameter Estimation in Surface Catalysis with Reaction Diffusion Fronts

J.G. Wade

Signal Processing and the Jacobi Group

D. Wallace 


\section{PREFACE}

The fourth Conference on Computation and Control was held at Montana State University in Bozeman, Montana from August 3-9, 1994. These proceedings represent the continued evolution of the cross-disciplinary dialogue begun at the 1988 conference (Volume 1 of PSCT) and continued on a biennial basis in 1990 and 1992. Those proceedings are housed in Volume 11 of PSCT and Volume 15 of PSCT, respectively.

In recent years considerable effort has been devoted to the problem of developing rigorous numerical methods and computational tools for control design and analysis. Although computational problems in control are extremely complex, these problems often have special structures that can be exploited to obtain both theoretical and computational results. Moreover, problems that arise from applications are best addressed by interdisciplinary approaches where experts in various disciplines (e.g. numerical analysis, control theory, fluid dynamics) come together and create numerical algorithms specifically for use in control design. This communication not only creates new mathematical tools, it often produces new research problems in the individual disciplines. This conference continues to bring together leading experts in control theory, numerical mathematics and various application areas to discuss recent developments in interdisciplinary approaches to computational control.

The organizers acknowledge the generous support of the Montana State University Foundation, the National Science Foundation's Division of Mathematical Sciences and the EPSCoR Program (Montana Group for Nonlinear Science). Montana State University and the city of Bozeman provided intellectual and aesthetic environment for this conference and the many individuals who gave their time are gratefully acknowledged. For more patient understanding that can be briefly summarized, the organizers thank their wives Sandy and Nancy.

Kenneth L. Bowers and John Lund Bozeman, March 17, 1995 


\section{CONTRIBUTORS}

Tom Banks, Center for Research in Scientific Computation, North Carolina State University, Raleigh, North Carolina 27695-8205

Ken Bowers, Department of Mathematical Sciences, Montana State University, Bozeman, Montana 59717-0240

John Burkardt, Interdisciplinary Center for Applied Mathematics Virginia Polytechnic Institute and State University, Blacksburg, Virginia, 24061

John Burns, Center for Optimal Design and Control, Interdisciplinary Center for Applied Mathematics, Virginia Polytechnic Institute and State University, Blacksburg, Virginia 24061

Chris Byrnes, Department of Systems Science and Mathematics,

Washington University, St. Louis, Missouri, 63130

Ruth Curtain, Mathematics Institute, University of Groningen, Netherlands

Alisa DeStefano, Department of Mathematics, College of the Holy Cross, Worcester, Massachusetts 01610

Per Enqvist, Department of Mathematics, Texas Tech University, Lubbock, TX 79409

Mark A. Erickson, RelMan, Inc., Mountain View, CA 94041

Rich Fabiano, Department of Mathematics, Texas A\&M University, College Station, Texas 77843

Ben Fitzpatrick, Department of Mathematics and Center for Research in Scientific Computation, North Carolina State University, Raleigh, NC 27695-8205

Dave Gilliam, Department of Mathematics, Texas Tech University, Lubbock, Texas 79409

Max Gunzburger, Interdisciplinary Center for Applied Mathematics, Department of Mathematics, Virginia Polytechnic Institute and State University, Blacksburg, Virginia 24061 
Robert Hoar, Department of Mathematical Sciences, Montana State University, Bozeman, MT 59717

Mary Jarratt, Department of Mathematics and Computer Science, Boise State University, Boise, Idaho 83725

Steven P. Kaliszewski, Department of Mathematics, University of Newcastle, Newcastle, NSW 2308 Australia

Belinda King, Department of Mathematics, Oregon State University, Corvallis, Oregon 97331

Julius King, Department of Mathematics and Center for Research in Scientific Computation, North Carolina State University, Raleigh, NC 27695-8205

Alan Laub, Dept. of Electrical and Computer Engineering, University of California, Santa Barbara, CA 93106-9560

Pamela Lockwood, Department of Mathematics, Texas Tech University Lubbock, TX 79409-1042

Siyuan Lu, Department of Mathematics, Texas Tech University, Lubbock TX 79409-1042

Nancy Lybeck, Center for Research in Scientific Computation, North Carolina State University, Raleigh, NC 27695-8205

Bernard Mair, Department of Mathematics, University of Florida, Gainesville, Florida 32611

Clyde Martin, Department of Mathematics, Texas Tech University, Lubbock, Texas 79409

Anne Morlet, Department of Mathematics, Ohio State University, Columbus, $\mathrm{OH}$ 43210-1174

Janet Peterson, Interdisciplinary Center for Applied Mathematics, Department of Mathematics, Virginia Polytechnic Institute and State University, Blacksburg, Virginia 24061

F. H. Ruymgaart, Department of Mathematics, Texas Tech University Lubbock, TX 79409 
Victor Shubov, Department of Mathematics, Texas Tech University Lubbock, TX 79409

Ralph Smith, Institute for Computer Applications in Science and Engineering, NASA Langley Research Center, Hampton, Virginia 23681

Frank Stenger, Department of Computer Science, University of Utah, Salt Lake City, Utah 84112

Steve Taylor, Department of Mathematical Sciences, Montana State University, Bozeman, Montana 59717-0240

John Tomlinson, Department of Mathematics, Texas Tech University Lubbock, TX 79409

Curt Vogel, Department of Mathematical Sciences, Montana State University, Bozeman, Montana 59717-0240

Gordon Wade, Institute for Scientific Computation, Texas A\&M University, College Station, Texas 77843

Dorothy Wallace, Department of Mathematics and Computer Science, Dartmouth College, Hanover, New Hampshire 03755

Yun Wang, Mathematical Products Division, Armstrong Laboratory Brooks AFB, TX 78235

Zaichao Xu, Departmnt of Mathematics, Texas Tech University, Lubbock TX 79409

Zhimin Zhang, Department of Mathematics, Texas Tech University, Lubbock TX 79409

Yishao Zhou, Mathematics Institute, University of Groningen, Netherlands 